\title{
Tumor-infiltrating lymphocytes in colorectal carcinoma
}

\author{
Shovana Karki ${ }^{1}$, Sanjib Pariyar ${ }^{1}$ \\ ${ }^{1}$ Department of Pathology, Institute of Medicine, Maharajgunj, Nepal
}

\section{Keywords:}

Colorectal carcinoma; Tumor-infiltrating lymphocytes; Tumor stage;

\section{Correspondence:}

Shovana Karki, MD

Associate Professor, Department of Pathology,

Institute of Medicine, Maharajgunj, Kathmandu, Nepal

ORCID ID: 0000-0001-5429-2422

Email: Shovana_karki@hotmail.com

Received : July $4^{\text {th }} 2021$; Accepted : August $9^{\text {th }} 2021$

Citation: Karki S, Pariyar S. Tumor-infiltrating lymphocytes in colorectal carcinoma. J Pathol Nep 2021;12(2):1859-63. DOI: 10.3126/jpn.v11i2.38227

Copyright: This is an open-access article distributed under the terms of the Creative Commons Attribution 4.0 International License, which permits unrestricted use, distribution, and reproduction in any medium, provided the original author and source are credited.

\section{INTRODUCTION}

Globally colorectal cancer (CRC) accounts for one of the commonest malignant tumors of the gastrointestinal tract. It is estimated that in all new cases of malignant tumors, the incidence and mortality of CRC are $10.2 \%$ and $9.2 \%$, respectively. ${ }^{1}$ As one-third of the patients undergoing curative resection die within five years of surgery it is important to provide individualized therapy as per risk stratification to improve prognosis. ${ }^{2}$ Immunotherapy has become an important modality of treatment for $\mathrm{CRC} .^{3-4} \mathrm{It}$ has been shown that in addition to tumor factors, the local tumor microenvironment (TME) i.e extracellular matrix, 


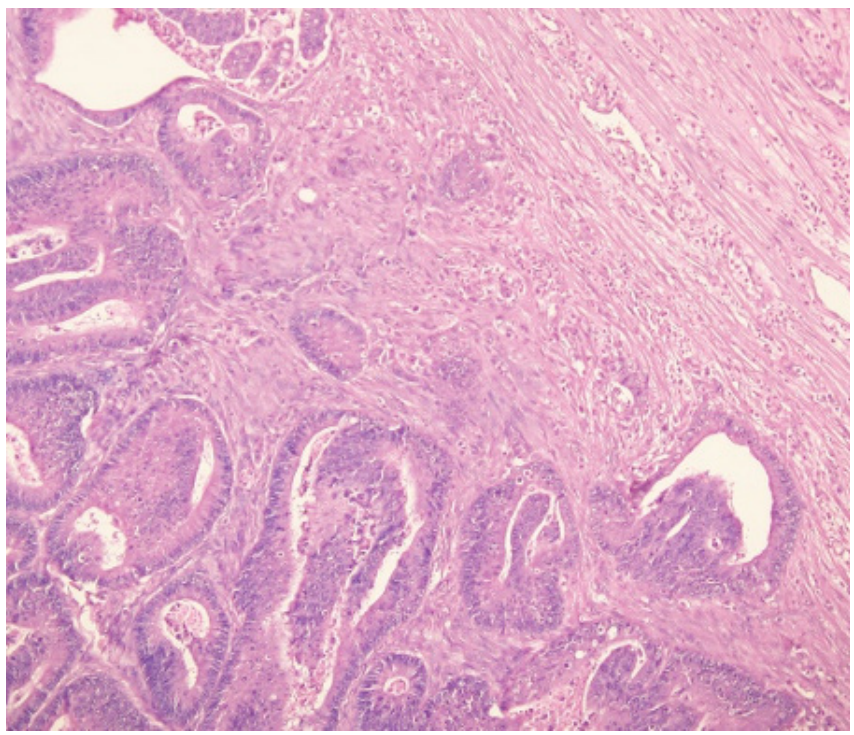

Figure 1: Low grade tumor infiltrating lymphocytes at the invasive tumor front of colonic adenocarcinoma (HE stain, X200)

immune cells, and cytokines play an important role in tumor proliferation, invasion, and metastasis. Thus, these are the prognostic indicators in colorectal carcinomas. ${ }^{5}$

The interactions among the different components of the tumor microenvironment mediate an immune response that is related to a favorable prognosis in colorectal cancer. The cells contributing to an effective immune response are CD8+ T cells of tumor-infiltrating lymphocytes (TIL) that have cytotoxic effects, $\mathrm{CD} 4+\mathrm{T}$ helper cells $(\mathrm{CD} 4+\mathrm{Th})$ that promote clonal expansion of antigen-specific CD8+ T cells and help in the production of IFN- $\gamma$, which thereby promote proliferation and functions of the effector molecules of CD8+ T cells and NK cells. ${ }^{10-11}$ Hence, it is reasonable to assess the activity of the immune system in tissue material, in the form of TILs present in the primary tumor. The present study aims to assess the TILs on $\mathrm{H}$ and E-stained sections in primary tumor front in patients with colorectal cancer and correlate it with other prognostic parameters.

\section{MATERIALS AND METHODS}

We retrospectively reviewed the database of the Department of Pathology, Institute of Medicine, Maharajgunj, Nepal. Cases of colectomy with a diagnosis of colorectal carcinoma were included in the study. Patients who had undergone neoadjuvant chemo/chemoradiotherapy were excluded from the study. $\mathrm{H}$ and $\mathrm{E}$ stained sections of the tumor were retrieved from the archives and tumor-infiltrating lymphocytes were counted as proposed. The analyses of TILs were performed in the invasive front of the primary tumor mass. Overall inflammatory reaction was assessed by using a four-degree scale. Score 0 indicated an absence of reaction, 1 weak, 2 moderate, and 3 severe. Score 0 meant no increase of inflammatory cells, 1 indicated a mild and patchy increase of inflammatory cells at the invasive

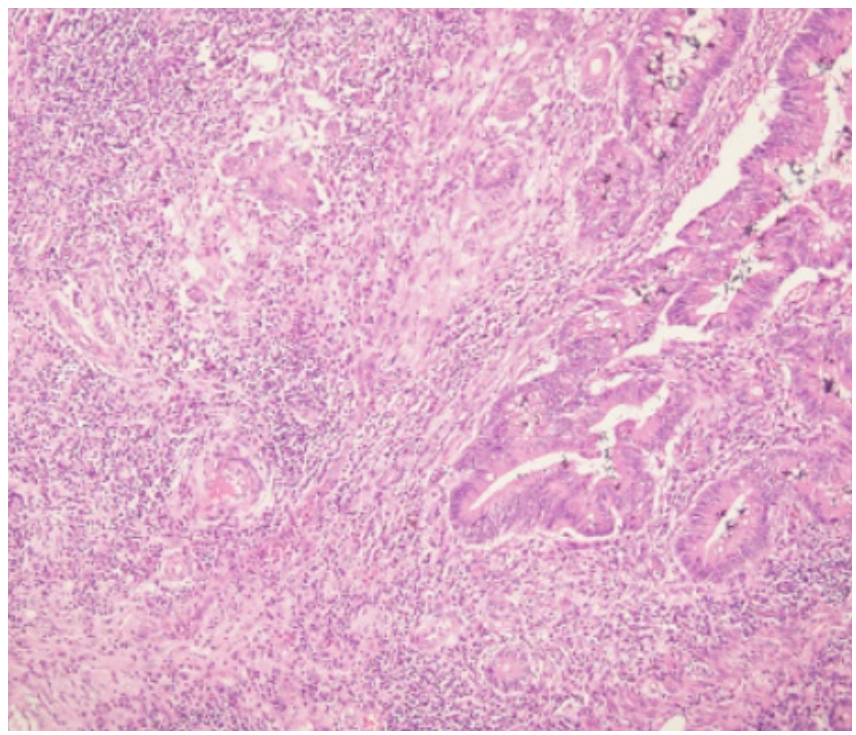

Figure 2: High grade tumor infiltrating lymphocytes at the invasive tumor invasive front (HE stain, X200)

margin, but with no destruction of invading cancer cell nests by the inflammatory cells. When inflammatory cells formed a band-like infiltrate at the invasive margin with a little destruction of cancer cell islets by inflammatory cells a score of 2 was given. A score of 3 denoted a very prominent inflammatory reaction, forming a cup-like zone at the invasive margin, and when the destruction of cancer cell nests was frequent and invariably present. ${ }^{8}$ Also, to conduct statistical analysis, we divided the study group into Group 1 (low)-(1 level of stromal TILs) and group 2 (high)-(2 and 3 levels of stromal TILs).

Other parameters i.e age, sex, size, location of the tumor, lymphovascular invasion (LVI), perineural invasion (PNI), $\mathrm{T}$ stage, $\mathrm{N}$ status, histological tumor type, and grade, resected margins were retrieved from the database of the department. The parameters were analyzed using SPSS 20. Correlation with different parameters was determined using Pearson correlation.

\section{RESULTS}

The study included 56 cases of colorectal carcinomas diagnosed on resection specimens received in the Department of Pathology from April 2019-September 2020. The study included 30 males and 26 females with an M: $F$ ratio of 1.15:1. The age ranged from 23-79years with a mean age of 54.3years. The tumors were predominant in the colon (50cases) than the rectum. Out of the colonic carcinomas, 21 cases $(42 \%)$ were located in the right side of the colon, 12 cases $(24 \%)$ were in the transverse colon, 2 cases $(4 \%)$ in the left-sided colon, and 15 cases (30\%)in the sigmoid colon.

Of all colorectal carcinomas, $32.1 \%$ had a weak level of TIL (fig. 1), 53.6\% moderate, and $14.3 \%$ strong levels 
Table 1A: Correlations between tumor-infiltrating lymphocytes and clinicopathological parameters

\begin{tabular}{|c|c|c|c|c|c|}
\hline \multirow{2}{*}{ Variables } & & \multicolumn{2}{|c|}{ Density of tumor-infiltrating lymphocyte } & \multirow{2}{*}{ Total (\%) } & \multirow{2}{*}{ p-value } \\
\hline & & Low & High & & \\
\hline \multirow{2}{*}{ Gender } & Male & 15 & 15 & $30(53.6 \%)$ & \multirow{2}{*}{0.5} \\
\hline & Female & 15 & 11 & $26(46.4 \%)$ & \\
\hline \multirow{2}{*}{ Site } & Colon & 25 & 25 & $50(89.2 \%)$ & \multirow{2}{*}{0.18} \\
\hline & Rectum & 5 & 1 & $6(10.8 \%)$ & \\
\hline \multirow{2}{*}{ Tumor Size } & $\leq 5 \mathrm{~cm}$ & 13 & 10 & $23(41.07 \%)$ & \multirow{2}{*}{0.76} \\
\hline & $>5 \mathrm{~cm}$ & 17 & 16 & $33(58.93 \%)$ & \\
\hline \multirow{4}{*}{ Depth of Invasion } & $\mathrm{T} 1$ & 0 & 1 & $1(1.8 \%)$ & \multirow{4}{*}{0.004} \\
\hline & $\mathrm{T} 2$ & 5 & 3 & $8(14.3 \%)$ & \\
\hline & $\mathrm{T} 3$ & 21 & 18 & $39(69.6 \%)$ & \\
\hline & $\mathrm{T} 4$ & 4 & 4 & $8(14.3 \%)$ & \\
\hline \multirow{3}{*}{ Lymphnode metastasis } & No & 17 & 16 & $33(58.9 \%)$ & \multirow{3}{*}{0.02} \\
\hline & $\mathrm{N} 1$ & 7 & 5 & $12(21.4 \%)$ & \\
\hline & N2 & 6 & 5 & $11(19.7 \%)$ & \\
\hline
\end{tabular}

Table 1B: Correlations between tumor-infiltrating lymphocytes and clinicopathological parameters

\begin{tabular}{|c|c|c|c|c|c|}
\hline \multirow{2}{*}{ Variables } & & \multicolumn{2}{|c|}{ Density of tumor-infiltrating lymphocyte } & \multirow{2}{*}{ Total (\%) } & \multirow{2}{*}{ p-valu } \\
\hline & & Low & High & & \\
\hline \multirow{2}{*}{$\begin{array}{l}\text { Lymphovascular } \\
\text { invasion }\end{array}$} & Positive & 15 & 10 & $25(44.6 \%)$ & \multirow{2}{*}{0.11} \\
\hline & Negative & 15 & 16 & $31(55.4 \%)$ & \\
\hline \multirow{2}{*}{ Perineural invasion } & Positive & 8 & 5 & $13(23.2 \%)$ & \multirow{2}{*}{0.08} \\
\hline & Negative & 22 & 21 & $43(76.8 \%)$ & \\
\hline \multirow{3}{*}{ Histological grade } & Grade 1 & 10 & 10 & $20(35.7 \%)$ & \multirow{3}{*}{0.09} \\
\hline & Grade 2 & 13 & 12 & $25(44.6 \%)$ & \\
\hline & Grade 3 & 7 & 4 & $11(19.7 \%)$ & \\
\hline \multirow{4}{*}{ Histological type } & Adenocarcinoma & 24 & 23 & $47(83.9 \%)$ & \multirow{4}{*}{0.004} \\
\hline & $\begin{array}{c}\text { Mucinous } \\
\text { adenocarcinoma }\end{array}$ & 3 & 2 & $5(5.4 \%)$ & \\
\hline & $\begin{array}{l}\text { Signet ring cell } \\
\text { carcinoma }\end{array}$ & 3 & 0 & $3(8.9 \%)$ & \\
\hline & MANEC & 0 & 1 & $1(1 \%)$ & \\
\hline \multirow{2}{*}{ Margin } & Positive & 1 & 2 & $3(8.9 \%)$ & \multirow{2}{*}{0.09} \\
\hline & Negative & 29 & 24 & $53(91.1 \%)$ & \\
\hline
\end{tabular}

of TILs (fig. 2). Colonic carcinomas had high-grade TIL as compared to rectal carcinomas. But it was statistically insignificant $(\mathrm{P}>0.17)$. The correlation of TIL with other parameters is displayed in table $1 \mathrm{~A}$ and $\mathrm{B}$.

\section{DISCUSSION}

Carcinomas of the colon and rectum are one of the commonest cancers worldwide. According to gender, CRC is the third most common cancer in men $(10 \%)$ and second in women $(9.2 \%){ }^{8}$

Fifty-six cases of colorectal carcinomas were reported in resection specimens in one year. Thirty cases were seen in males and twenty-six cases were seen in females. Age ranged from 11-79 years with a mean age of 54.3 years. In a similar study by Andreoni et al slightly higher number of cases was seen in males as compared to females. The age ranged from 24-88yrs, mean 63yrs. ${ }^{6}$ Another study by Shah et showed 37 cases of colorectal carcinomas in males and 36 cases in females. They reported a mean age of 52 years. ${ }^{7}$

The carcinomas were mostly localized to the colon (50cases). Out of the colonic carcinomas, 21 cases $(42 \%)$ were located in the right side of the colon, 12 cases $(24 \%)$ were in the transverse colon, 2 cases $(4 \%)$ in the left-sided colon, and 15 cases $(30 \%)$ in the sigmoid colon. Andreoni et al also found carcinomas predominantly localized to the colon rather than the rectum. ${ }^{6}$ Another study reported adenocarcinomas located mostly in the sigmoid followed by rectum and caecum. ${ }^{9}$ 
Histologically, all colorectal carcinomas were adenocarcinomas in this study. In a study of histology of colorectal cancer, 96\% were adenocarcinomas and other carcinomas included epidermoid carcinomas (squamous cell carcinomas) and carcinoids. ${ }^{9}$ They found that mucinous and signet ring cell carcinomas were more common in the younger age group. ${ }^{9}$ In this study, signet ring cell carcinomas were found in the younger age group. Another study by Nitsche reported mucinous adenocarcinoma more commonly in the right side of the colon. ${ }^{10}$ All signet ring cell carcinomas and 50\% of mucinous carcinomas were localized to the right side of the colon in our study. The number of mucinous adenocarcinomas and signet ring cell carcinomas was slightly higher in females as compared to males. With regards to mucin secreting tumors, a study found a higher proportion of these tumors in females. ${ }^{11}$

We found that moderately differentiated adenocarcinoma was the commonest histological grade, similar to a study by Stewart et al. ${ }^{9}$ The TNM status showed most of the adenocarcinomas presenting in $\mathrm{T} 3$ and N0 status. This is similar to Nitsche et al's findings in their study of colorectal carcinomas. ${ }^{9}$

Circumferential resection margin (CRM) was the margin that was positive in all three margin positive cases. Histologically, they were adenocarcinomas with predominantly $\mathrm{T} 3$ status. A study by Balboa et al found CRM as the margin which was predominantly involved by tumor. ${ }^{12}$

It is stated in the literature that lymphocytic infiltration is a major immunological defense against tumor cells in solid tumors and is a potential predictor of colorectal cancer. ${ }^{13-15}$ We found that TIL was weak in $32.1 \%$, moderate in $53.6 \%$, and strong in $14.3 \%$ of all colorectal cancers. In a similar study, weak infiltration was seen in 72 cases, moderate in 30 cases, and strong in 21 cases. $^{16}$ Colonic carcinomas (50\%) presented with a high grade of TIL whereas only $16.6 \%$ of rectal cancers presented with high TIL. But this was not statistically significant (p-value 0.17 ). Other studies also reported the same. ${ }^{16}$

APC-lymphocytes stimulate the TIL, the degree and direction of activation and selectivity of stromal TILs depend on the type of antigen present on the tumor cell. ${ }^{17}$ The first host defense against invasive tumor cells that further stimulate or inhibit the cellular response is provided by TILs located in the invasive tumor fronts. ${ }^{18}$ We noted in this study that tumors with low TIL presented with a higher $\mathrm{T}$ and $\mathrm{N}$ status. In brief, we found a statistically significant correlation between the $\mathrm{T}$ and $\mathrm{N}$ status of cancers and the degree of TILs. A study by Jakubowska et al found a low incidence of TILs in the invasive tumor front associated with metastases to the local lymph nodes and extension of tumor beyond the nodule to the surrounding tissues. ${ }^{16}$ These results are consistent with the observations of other studies by Perez et al ${ }^{13}$,Huh et a ${ }^{19}$, and Pagès et al. ${ }^{20}$ The decrease in intratumoral immune T-cell densities correlated with the growth of the primary tumor and the metastatic spread in a study by Mlecnik et al. ${ }^{21}$

Though a low grade of TIL infiltration was associated withLVI and PNI, it was not statistically significant in this study. However other studies have found a significant correlation between TIL and LVI and PNI. ${ }^{16}$

TILs were assessed in invasive tumor margins. Literature reports inflammatory reaction at the invasive margin as the predictor for both survival and recurrence-free survival. Macrophages and lymphocytes were the most valuable individual cell types as predictors of inflammatory response. In colorectal carcinomas, results indicate that $\mathrm{CD} 8+$ and FOXP3+ infiltrating cells, but not $\mathrm{CD} 3+\mathrm{T}$ cells were the prognostic markers for disease-free survival and overall survival. $^{5}$

\section{CONCLUSIONS}

Inflammatory reactions at the invasive tumor front can be easily analyzed in resection specimens of colorectal cancers without additional costs. Low-grade TIL is indicative of high-stage tumors with a poor prognosis. Hence, the inclusion of TIL in pathological reports for risk stratification of the patient is mandatory.

\section{Conflict of interest: None}

\section{REFERENCES}

1. Bray F, Ferlay J, Soerjomataram I et al. Global cancer statistics 2018: GLOBOCAN estimates of incidence and mortality worldwide for 36 cancers in 185 countries. CA Cancer J Clin. 2018;68:394-24. Crossref

2. Mcardle CS, Hole DJ. Outcome following surgery for colorectal cancer: analysis by hospital after adjustment for case-mix and deprivation. Br J Cancer 2002;86:331-5. Crossref

3. Arora SP, Mahalingam D. Immunotherapy in colorectal cancer: for the select few or all? J Gastrointest Oncol. 2018;9:170-9. Crossref

4. Kalyan A, Kircher S, Shah H, et al. Updates on immunotherapy for colorectal cancer. J Gastrointest Oncol. 2018;9:160-9. Crossref

5. Zhao, Y., Ge, X., He, J. et al. The prognostic value of tumorinfiltrating lymphocytes in colorectal cancer differs by anatomical subsite: a systematic review and meta-analysis. World J Surg Onc. 2019;17:85. Crossref

6. Stewart B., Wild C.P., editors. World Cancer Report 2014. International Agency for Research on Cancer (IARC); Lyon, France: 2014. Website 
7. Andreoni B, Chiappa A, Bertani E et al. Surgical outcomes for colon and rectal cancer over a decade: results from a consecutive monocentric experience in 902 unselected patients. World J Surg Oncol. 2007;5:73. Crossref

8. Shah S, Shrestha S, Shah JN et al. Clinico-pathological characteristics of colorectal carcinoma at university teaching hospital, Nepal. Journal of Patan Academy of Health Sciences. 2014;1:35-8. Crossref

9. Stewart SL, Wike JM, Kato I et al. A population-based study of colorectal cancer histology in the United States, 1998-2001. Cancer, 2006;7:1128-41. Crossref

10. Nitsche U, Stögbauer F, Späth C et al.Right Sided Colon Cancer as a Distinct Histopathological Subtype with Reduced Prognosis. Dig Surg 2016;33:157-63. Crossref

11. Kang H, O'Connell JB, Maggard MA et al. A 10-year outcomes evaluation of mucinous and signet-ring cell carcinoma of the colon and rectum. Dis Colon Rectum 2005;48:1161-8. Crossref

12. Balbaa AM, Elkady N, Abdelrahman EM. Predictive Factors of Positive Circumferential and Longitudinal Margins in Early T3 Colorectal Cancer Resection. International Journal of Surgical Oncology volume 2020. Article ID 6789709. Crossref

13. Perez RO, Habr-Gama A, dos Santos RM et al. Peritumoral inflammatory infiltrate is not a prognostic factor in distal rectal cancer following neoadjuvant chemoradiation therapy. J Gastrointest Surg. 2007;11:1534-40. Crossref

14. Li Y, Liang L, Dai W et al. Prognostic impact of programed cell death-1 (PD-1) and PD-ligand 1 (PD-L1) expression in cancer cells and tumor infiltrating lymphocytes in colorectal cancer. Mol Cancer. 2016;15:55. Crossref
15. Thomas GD, Dixon MF, Smeeton NC, et al. Observer variation in the histological grading of rectal carcinoma. J Clin Pathol 1983;36:38591. Crossref

16. Jakubowska K, Koda M, Kisielewski W et al. Tumor-infiltrating lymphocytes in primary tumors of colorectal cancer and their metastases. Exp Ther Med. 2019;18:4904-12. Crossref

17. Galon J, Costes A, Sanchez-Cabo Fet al. Type, density, and location of immune cells within human colorectal tumors predict clinical outcome. Science. 2006;313:1960-64. Crossref

18. LeBoit G, Burg G, Weedon D, Sarasin A, editors. IARC Press; Lyon: 2005. Pathology and Genetics of Skin Tumours. 355p.

19. Huh JW, Lee JH, Kim HR. Prognostic significance of tumorinfiltrating lymphocytes for patients with colorectal cancer. Arch Surg. 2012;147:366-72. $\underline{\text { Crossref }}$

20. Pagès F, Galon J, Fridman WH. The essential role of the in situ immune reaction in human colorectal cancer. J Leukoc Biol. 2008;84:981-7. Crossref

21. Mlecnik B, Tosolini M, Kirilovsky A et al. Histopathologic-based prognostic factors of colorectal cancers are associated with the state of the local immune reaction. J Clin Oncol. 2011;29:610-18. $\underline{\text { Crossref }}$ 